\title{
Case Study Evaluation of an Initiative to Help Small and Limited-Resource Farmers Supply Produce Commercially
}

\author{
Barrett Vaughan, Ph.D. \\ Associate Professor \\ College of Agriculture, Environment, and Nutrition Sciences \\ Tuskegee University \\ Henderson Hall \\ Tuskegee, Alabama U.S.A. 36088
}

\begin{abstract}
The evaluation of a university-based initiative to assist small and limited-resource farmers to supply produce commercially is presented as a case study that examined sample findings in the areas of research, extension, education and integration, and enterprise, which described the business aspect. The sample findings presented were from research efforts to provide sustainable irrigation, extension efforts to provide integrated pest management training, integrated efforts to provide food safety training and technical assistance, and an economic assessment of the impacts on the household economy. Although it may be validly argued to the contrary, it was concluded that the findings from the various efforts in research, extension, and enterprise were significant and substantial. The examination of all four areas was shown to provide a broader, more comprehensive evaluation of the program.
\end{abstract}

Keywords: Small Farmers, Produce Markets, Commercial Supply, Economic Assessment

\section{Introduction and Approach}

There are several methods of examining the progress and achievements made in the six years of a multidisciplinary, university-based research and extension initiative to assist small and limited resource farmers to remain sustainable by supplying produce to a major commercial retailer. The initiative involved a significant portion of the research and extension personnel resources and a substantial amount of accessible federal and state resources were leveraged towards the effort.

As a result, it is estimated that between one and two dozen farms supplied produce commercially between 2011 and 2016. However, around 100 farmers showed a significant interest in participating with the initiative. Moreover, several hundred farmers received extension or outreach training and technical assistance related to potentially supplying produce commercially through several dozen workshops and presentations on topics such as production, irrigation, integrated pest management, harvesting and labor contracting, grading, food safety, etc. In terms of the aggregate value of produce supplied over the duration of the project, about two million dollars in revenues have been realized for the participating farmers.

Nevertheless, the approach to this case study evaluation of the initiative is focused through the lens of the major areas which are appropriate for agricultural and business-related studies, i.e., research, extension, education and integration, and enterprise. This is not intended to be an exhaustive or comprehensive review of the efforts undertaken in the initiative, but to give examples of the highlights and challenges under each of the four areas to provide an example of how such projects might be evaluated.

\section{Area Definitions, Goals, and Sample Findings}

\subsection{Research}

Research is the creation of new knowledge through the use of scientifically-proven methods. The overall goal of the initiative was to determine if it was possible for small and limited resource farmers to supply produce to a commercial buyer. 
This effort was novel in that most of these farmers would not normally supply commercially but sell produce through farmers' markets, direct to the consumer, or use smaller market outlets such as local grocery stores, restaurants, schools, etc. Sound research was critical in providing a basis for the assistance given to the farmers to make these changes. There were several key research efforts as part of the initiative; however, one of the more important efforts involved the utilization of irrigation at small and limited resource farms. Irrigation is a key component of any farm that is supplying produce commercially, as it helps to manage risk, stabilize the rate of production, and maintain plant health and salability.

Shange et al. (2014) explored the effectiveness of deploying sustainable irrigation systems at socially and historically disadvantaged farmers (SHDF). The objective was "to increase the capacity of SHDFs in order for them to become full participants in modern food systems at the commercial level." These systems included both micro-irrigation (drip) and solar powered irrigation, which were configured for use at a specific small farm. Shange reported highlights from three of the farms at which systems were installed stating that the systems, "will allow for more consistent and sustainable production in the future," and that the small acreage "can be optimized for production."

For evaluating progress in the area of research, qualitative measurable results are usually generated. In this type of project, these results may take the form of increases in yield, quality of harvested product, moisture content, acreage irrigated, etc. In addition, the results may be in quantifying scholarly products, such as journal articles published or student theses.

\subsection{Extension}

Extension programs provide science-based knowledge to people through informal education opportunities with the purpose of producing changes in knowledge, behavior, and condition. Extension was involved from the very beginning of the initiative in providing information to farmers who were involved and interested in the effort. A key component that essentially required a more hands-on approach, in the field style of training and technical assistance, was integrated pest management (IPM). For the small farmers in this initiative, because of the high standards, any non-conformities, such as low weight, disease or predation scars, could mean the loss of all sales. IPM not only addressed insect pests, but also any fungal, bacterial, and weed related production issues.

Quarcoo and Bonsi (2014) "document[ed] the IPM activities associated with supplying produce [commercially]; summarize[d] pest problems encountered on the afore-stated crops; recommend[ed] IPM methods suitable for limited resource farmers; and suggest[ed] other activities that ensure[d] that farmers incur even less pest-related crop losses." A host of specific extension activities were carried out for several years that focused on the crops marketed through the initiative, i.e., watermelon, purple hull peas, and collard greens, and the pests that were the most prevalent. In evaluating the extension efforts, Quarcoo and Bonsi found "major improvements in both the knowledge and confidence with which farmers identified insect pests." It was concluded that "[1]imited resource farmers... have made major strides as far as IPM is concerned [as the] initiative... provided an additional impetus to learn and adopt more of its practices."

Evaluation in extension usually takes the form of outputs and outcomes, where the outputs are usually a quantification of the activities or participants therein and the outcomes are some measurements of change in knowledge, behavior, or condition. In this type of project, the outputs would be the numbers of workshops or trainings hosted and the number of participants. Outcomes, however, would need to be measured some time after the effort and can be gauged immediately from a pre and post test, for example, or some time afterwards by records of how the farmers utilized the practices that they learned in the extension program. There may also be more programmatic outputs such as the number of publications, such as curricula, bulletins, fact sheets, etc. and the distribution thereof measured by printings or downloads.

\subsection{Education and Integration}

The quality of education for students at an institution may be enhanced through directed, planned involvement in research and extension efforts, as it provides them with an experiential, real-world learning component. The involvement of students was key to the progress of certain aspects of the initiative, mainly with post-harvest handling and preparation. Integration, similarly, is the planned and beneficial interaction between research and extension personnel and assets to produce a targeted, rigorous, and broadly disseminated and assimilated result. Integration has been a key facet of making sure that the farmers in the initiative were able to take advantage of this market opportunity through obtaining food safety certification. 
Since the first year of the initiative, a team of faculty and staff members have worked together to assist the farmers involved to keep the records, train workers, and make the changes to their farms necessary to become produce Good Agricultural Practices (GAP) certified, a strict requirement from the commercial buyer.

Vaughan et al. (2014) chronicled the numerous strategies employed to provide effective training and technical assistance to the farmers with this task. These techniques included large group meetings, small group sessions, conference calls, on-farm visits and mock audits, and visits to commercial farms. These techniques involved the integration of research and extension, not only of the persons involved, but also in making sure that the materials and methods were effective. Research and extension personnel were involved directly in assisting the farmers with receiving training and technical assistance, completing paperwork and forms, and addressing questions that the farmers had concerning the certification audits. Nevertheless, the number of farmers that became food safety certified in that period was less than expected, although more became GAP certified in later years.

Quantifying the results from education and integration are manifold. Education results may take the form of the number of students involved in directly in the project and with publications. It may also be an evaluation of the increase in learning that the students experience, or the quality of the involvement in the project that the students report. As to integration, the evaluation would be more specific to the project and quality of integration. Goals for integration may have been stated specifically in terms of efforts or teams that included resources from different areas, or the persons involved in such efforts.

\subsection{Enterprise}

An enterprise, according to the Merriam-Webster Dictionary, is "a unit of economic organization or activity; especially a business organization; a systematic purposeful activity." The effort undertaken in the initiative by the cooperating farmers was, primarily, a business. In collaboration with a cooperative representing the participating farmers, university faculty and staff carried out most of the business functions necessary to facilitate the successful supply of produce from the farmers, through intermediate steps and entities, to the commercial buyer. In terms of failure or success of the initiative as an enterprise, two aspects are examined. First, is whether the effort succeeded or failed at operating as an enterprise. Second, is whether the farmers succeeded or failed to be profitable.

Towards the first aspect, Vaughan et al. (2017) attempted to qualitatively inventory the personnel and materiel needed through the initiative, with the cooperative, in order to facilitate the farmers to supply produce commercially. Produce of some variety was shipped to the commercial buyer every year of the project, even despite crop failures, diseases, labor shortages, and other production difficulties. Federal and state funds were utilized extensively to provide the facilities, equipment and supplies, buildings, trucks, containers, coolers, etc. that were vital to the functioning of the initiative.

In terms of whether the farmers succeeded or failed to be profitable, Karki et al. (2017) assessed the impact of the initiative on the household economy of the farmers involved. The study "applied the triangulation approach to collect field data... and conducted a case study using quantitative and qualitative tools to measure socioeconomic and environmental impacts." A few key findings of the assessment were calculations of the Commodity Factor Productivity and Total Factor Productivity which are "measures [of] the efficiency of farmers in combining the available inputs to produce a unit of output" for selected farm operations and of employment creation. Karki et al. (2017) concluded that the farmers in the initiative "benefitted enormously" based on a variety of economic and societal factors.

Nevertheless, several of the participating farmers disclosed that they were not profitable. This was anecdotally due to several factors such as loan obligations, payment delays, and production problems that did not allow them to enjoy the full benefits of the revenues earned. Evaluation of this vital area would be either organizational or financial. Examples of organizational results would be quantifying the effort expended to coordinate the farmers or to aggregate the produce in hours or dollars. Financial results, for example, would be average or total farm revenues or profits reported. Also, the amount of additional marketing outlets attained by the farmers or additional revenues from those outlets would be quantifiable results in this area.

\subsection{Discussion and Conclusion}

Overall, an argument can be made that the initiative was not entirely successful. The research objectives were met, but not applied broadly. The extension effort was perhaps the most effectual but was not so in all areas needed. 
The education and integration involved a few of the students, yet several of the efforts involved close collaborations between research faculty, extension specialists, extension agents, and research-outreach personnel to provide integrated training and technical assistance services. Although the enterprise, through the formation of the cooperative, was functional and produced definable profits, there were persistent issues with group cohesiveness, leadership and management, financial stability, and production sustainability.

However, any objective evaluator would have to observe that the initiative did accomplish what it set out to do. From a research standpoint, the effort did explore and document what would be necessary to incorporate small and limited resource farmers into the pool of commercial produce suppliers. Much of the extension personnel were galvanized through the initiative towards the goal of providing the science-based information necessary to assist the farmers to be able to supply produce commercially. The effort brought a high level of integration between once-detached research and extension personnel and focused the leveraging of government funds towards the sustainability of clientele. In addition, the initiative developed and refined, through much trial and error, a model for small farmers to be profitably and sustainably integrated into the global food system.

It is not objectively possible to determine if the initiative was a success or a failure. However, the "fruits" of this labor are still significant, substantial, and sustaining. This evaluation of the initiative by examining the results in the four areas of research, extension, education and integration, and enterprise - instead of just one or two areasprovided a broader and more comprehensive view of how to determine the value and benefits of such programs.

\section{References}

Karki, L.B., W.A. Hill, R. Shange, T.M. Hargrove, M.D. Robinson, B. Vaughan, N. Baharanyi, G. Wall, G. Hunter, and K. Pace. (2017) "Assessing the Impact of the Small Farmer-Tuskegee University-Walmart Project on the Household Economy of Small and Limited Resource Farmers in Alabama." Professional Agricultural Workers Journal 4 (2): 1-15, Article \# 4.

Quarcoo, F. and C. Bonsi. (2014). "Overview of the Integrated Pest Management (IPM) Terrain and Activities in Furtherance of the Walmart Initiative to Purchase Fresh Vegetables from Local Growers in Alabama." Professional Agricultural Workers Journal 1 (2): 1-14, Article \# 8.

Shange, R., R. Martin, V. Khan, K. Daniels, G.X. Hunter, G. J. Johnson, S. Musser, W. Puckett, and W.A. Hill. (2014). "Extending Sustainable Irrigation Opportunities to Socially and Historically Disadvantaged Farmers in the Alabama Black Belt to Support Commercial-Level Production." Professional Agricultural Workers Journal 1 (2): 1-8, Article \# 3.

Vaughan, B., A. Zeigler, G.D. Wall, M.D. Robinson, W.A. Hodge, C.O. Bonsi, N.R. Baharanyi, and W.A. Hill. (2014). "Case Study of a Food Safety/Good Agricultural Practices (GAPs) Educational Program for Small and Limited Resource Produce Farmers.” Professional Agricultural Workers Journal 1 (2): 1-7, Article \# 7.

Vaughan, B., M. D. Robinson, A. Zeigler, G. Hunter, G. Wall, J. Brown, R. Ellington, and W. A. Hill. (2017) "The Walmart Initiative: Observations of the Steps within Commercial Supply." Professional Agricultural Workers Journal 4 (2): 1-20, Article \# 5. 